\title{
Concentrate for Concentrate for Solution for Infusion Dosage Form
}

National Cancer Institute

\section{Source}

National Cancer Institute. Concentrate for Concentrate for Solution for Infusion Dosage

Form. NCl Thesaurus. Code C149383.

Liquid sterile preparation intended to be diluted in the specified liquid to obtain a

concentrate for solution for infusion, which in turn is intended to be diluted in the specified liquid to obtain a solution for infusion. 